LA-UR-97,, 894

\author{
Title: \\ CONF-970707-- \\ INFLUENCE OF TEMPERATURE ON THE \\ HIGH-STRAIN RATE MECHANICAL \\ BEHAVIOR OF PBX 9501. \\ REOE WED
NOV 031997 \\ $08 \pi 1$ \\ Author(s): \\ G.T. Gray III, W.R. Blumenthal, D.J. Idar, C.M. Cady \\ Materials Science and Technology Division \\ Los Alamos National Laboratory \\ Los Alamos, NM 87545
}

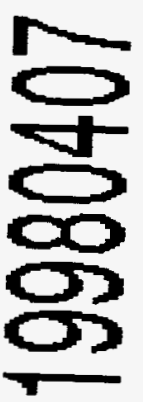

Presented at:

APS Topical Conference on Condensed Matter Physics

To be submitted to:

University of Amherst, Mass.

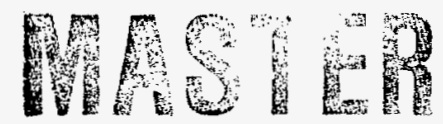
July 27 - August 1, 1997

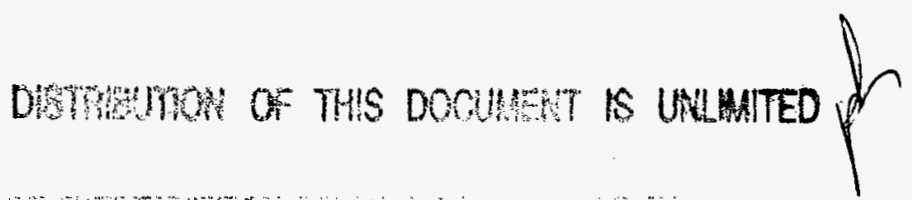

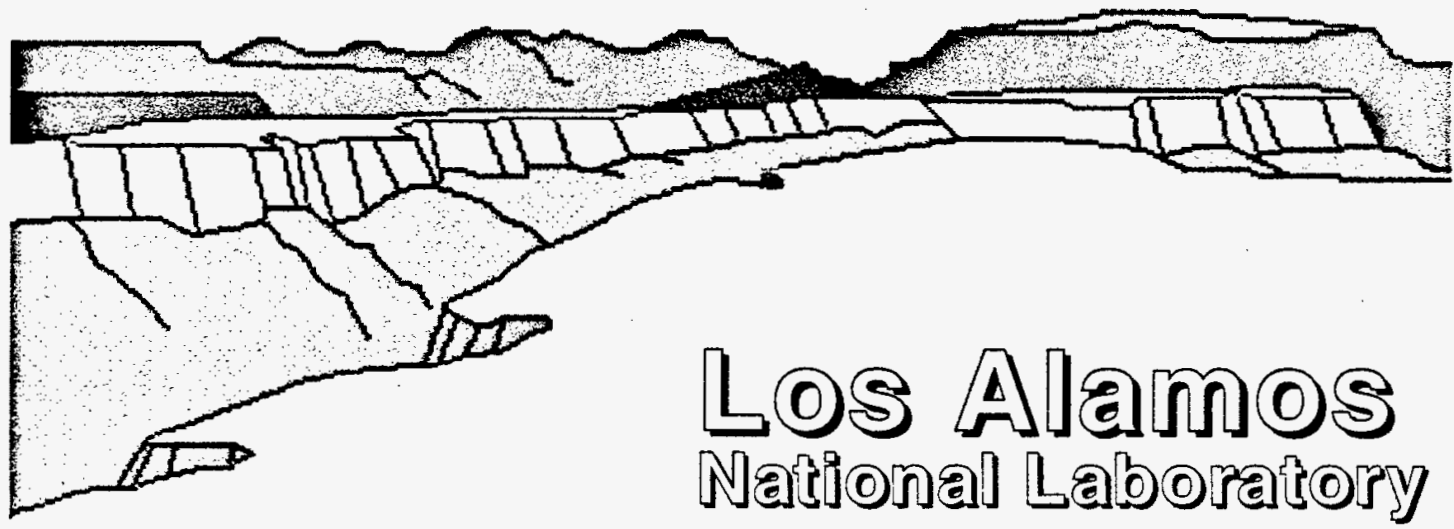

Los Alamos National Laboratory, an affirmative action/equal opportunity employer, is operated by the University of California for the U.S. Department of Energy under contract W-7405-ENG-36. By acceptance of this article, the publisher recognizes that the U.S. Government retains a nonexclusive, royaltyfree license to publish or reproduce the published form of this contribution, or to allow others to do so, for US Government purposes. The Los Alamos free license to pubilsh or reproduce the published form of this contribution, or to allow others to do So, for U.S. Government purposes. The
National Laboratory requests that the publisher identify this article as work performed under the auspices of the U.S. Department of Energy.

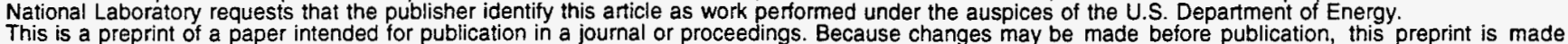
available with the understanding that it will not be cited or reproduced without the permission of the author. 


\section{DISCLAIMER}

This report was prepared as an account of work sponsored by an agency of the United States Government. Neither the United States Government nor any agency thereof, nor any of their employees, makes any warranty, express or implied, or assumes any legal liability or responsibility for the accuracy, completeness, or usefulness of any information, apparatus, product, or process disclosed, or represents that its use would not infringe privately owned rights. Reference herein to any specific commercial product, process, or service by trade name, trademark, manufacturer, or otherwise does not necessarily constitute or imply its endorsement, recommendation, or favoring by the United States Government or any agency thereof. The views and opinions of authors expressed herein do not necessarily state or reflect those of the United States Government or any agency thereof. 


\title{
INFLUENCE OF TEMPERATURE ON THE HIGH-STRAIN- RATE MECHANICAL BEHAVIOR OF PBX 9501
}

\author{
G.T. Gray III, W.R. Blumenthal, D.J. Idar, and C.M. Cady \\ Los Alamos National Laboratory, Los Alamos, NM 87545
}

High-strain-rate $\left(2000 \mathrm{~s}^{-1}\right)$ compression measurements utilizing a specially-designed Split-Hopkinson-Pressure Bar have been obtained as a function of temperature from -55 to $+50^{\circ} \mathrm{C}$ for the plastic-bonded explosive PBX 9501. The PBX 9501 high-strain-rate data was found to exhibit similarities to other energetic, propellant, and polymer-composite materials as a function of strain rate and temperature. The high-rate response of the energetic was found to exhibit increased ultimate compressive fracture strength and elastic loading modulus with decreasing temperature. PBX 9501 exhibited nearly invariant fracture strains of $\sim 1.5$ percent as a function of temperature at high-strain rate. The maximum compressive strength of PBX 9501 was measured to increase from $\sim 55 \mathrm{MPa}$ at $50^{\circ} \mathrm{C}$ to $150 \mathrm{MPa}$ at $-55^{\circ} \mathrm{C}$. Scanning electron microscopic observations of the fracture mode of PBX 9501 deformed at high-strain revealed transgranular cleavage fracture of the HMX crystals.

\section{INTRODUCTION}

The high-strain-rate stress-strain response of energetic materials has received increased interest in recent years related to: 1) the need for predictive constitutive model descriptions for use in largescale finite-element simulations of collateral damage and energetic systems safety, and 2) focused emphasis on understanding the dynamics of localization phenomena and mechanical failure of polymeric composites, including energetics. The establishment of more physically-based constitutive models to describe complex loading processes and energetics requires a detailed knowledge of the separate and synergistic effects of temperature and strain rate on the mechanical response of PlasticBonded eXplosives (PBX's).

A significant number of previous studies have probed the constitutive response of a wide variety of plastic-bonded explosives(1-8). Beginning with the high-rate Hopkinson split-bar studies of Hoge(1) on a range of PBX's and continuing with the highstrain rate work of Field(3,5), Palmer(6), and
Walley it has been found that: a) the effective elastic modulus of PBX's are strongly influenced by strain rate and temperature, b) PBX's during highrate loading continue straining after the maximum flow stress has been achieved, i.e. viscoelasticplastic behavior is indicated, c) stress wave propagation through PBX's and their susceptibility to shear failure is such that sample-size and lubrication effects are important. Low-strain-rate studies on PBX's by Peeters(2), Wiegand $(4,7)$ and Funk (8) have similarly shown that the compressive strength (maximum stress) and the loading modulus increase with decreasing temperature and increasing strain rate. The work of Wiegand $(4,7)$ has further shown a linear correlation between compressive strength and modulus in addition to a constant critical strain to fracture, independent of loading rate in compression or temperature, for a range of PBX's. This observation suggests a critical tensile stress criterion to initiate brittle fracture similar to ceramic materials. 
The objective of this paper is to present results illustrating the effect of systematic variations of strain rate and temperature at high-strain rate on the constitutive response of PBX 9501.

\section{EXPERIMENTAL TECHNIQUES}

This investigation was performed on the plasticbonded explosive PBX 9501. PBX 9501 is a formulation composed of $95 / 2.5 / 2.5 / 0.1$ weight percent of $\mathrm{HMX} /$ Estane (a copolymer) / a eutectic mixture of bis(2,2 dinitropropyl)acetal and bis(2,2-dinitropropyl)formal [abbreviated BDNPAF] / and Irganox (a free radical inhibitor). A molding powder is prepared by the slurry method. The powder is then preheated and pressed to a cylindrical billet in a steel die.

Cylindrical compression samples $6.35-\mathrm{mm}$ in diameter by $6.35-\mathrm{mm}$ in length were machined from the starting billet of PBX 9501 for the high-rate tests. Quasi-static compression tests were conducted at strain rates of 0.001 and $0.1 \mathrm{~s}^{-1}$ at $298 \mathrm{~K}$ in laboratory air exhibiting a relative humidity of $\sim 15 \%$. Dynamic tests were conducted as a function of strain rate, $1500-7000 \mathrm{~s}^{-1}$, and temperature, -55 to $50^{\circ} \mathrm{C}$, utilizing a splitHopkinson pressure bar. The split-Hopkinson bar used for this study was equipped with $9.4-\mathrm{mm}$ diameter Ti-6Al-4V bars that improve the signal-tonoise level needed to test extremely low strength materials as compared to the maraging steel bars traditionally utilized for Hopkinson-Bar studies on metallic materials.

The inherent oscillations in the dynamic stressstrain curves and the lack of stress equilibrium in the specimens at low strains make the determination of yield strength inaccurate at high strain rates. Temperature variations between -55 and $50^{\circ} \mathrm{C}$ on a split-Hopkinson bar have been achieved utilizing a specially-designed gas manifold system developed at the Los Alamos National Laboratory (LANL) where samples were cooled and heated using helium ( $\mathrm{He}$ ) gas within a 304-stainless steel containment chamber held at a partial vacuum. The He gas is cooled below ambient temperature by passing the He through a copper coil positioned within a liquid nitrogen dewar, while elevated temperatures are achieved by heating the $\mathrm{He}$ in a similar coil within a glycerin-filled beaker warmed to $-100^{\circ} \mathrm{C}$ by a heating plate. Samples were lubricated using either a thin layer of molybdenum disulfide grease or molybdenum disulfide spray lubricant.

\section{RESULTS AND DISCUSSION}

The compressive true-stress versus true-strain response of PBX 9501 was found to depend on the applied strain rate, varied between 0.001 and $2000 \mathrm{~s}^{-}$ ${ }^{1}$, and the test temperature, varied between $-55^{\circ} \mathrm{C}$ and $50^{\circ} \mathrm{C}$ at a strain rate of $3000 \mathrm{~s}^{-1}$. The yield strength of PBX 9501 at $25^{\circ} \mathrm{C}$ is shown in Figure 1 to increase from $\sim 8 \mathrm{MPa}$ at $0.0011 \mathrm{~s}^{-1}$ to $10 \mathrm{MPa}$ at $0.11 \mathrm{~s}^{-1}$ to $\sim 50 \mathrm{MPa}$ at a strain rate of $2000 \mathrm{~s}^{-1}$ accompanied by an $\sim 7$-fold increase in apparent loading modulus. These results are consistent with previous strain rate studies on PBX 9501(2,7). Due to the documented dispersive nature of wave propagation in ductile polymers and plastic-bonded energetics and the potential influence of sample size on attaining a uniform stress state, the high-rate constitutive response of PBX 9501 was carefully probed to obtain well-posed and accurate data.

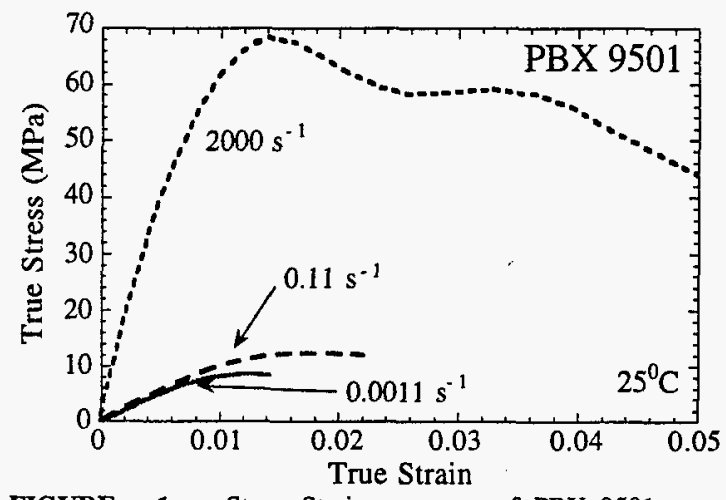

FIGURE 1: Stress-Strain response of PBX 9501 as a function of strain rate at $25^{\circ} \mathrm{C}$.

To assure well-posed high-rate measurements on PBX 9501, it is instructive to examine the different analyses(9) used to calculate sample stress from the Hopkinson bar strain as shown in Figure 2a. In the 1-wave analysis the sample stress is directly proportional to the bar strain measured from the transmitted bar. The 1-wave stress analysis reflects the conditions at the sample-transmitted bar interface and is often referred to as the sample "back 
stress". Alternatively in a 2-wave analysis, the sum of the synchronized incident and reflected bar waveforms (which are opposite in sign) is proportional to the sample "front stress" and reflects the conditions at the incident/reflected bar-sample interface. This analysis results in more accurate and smoother stress-strain curves, especially near the yield point.
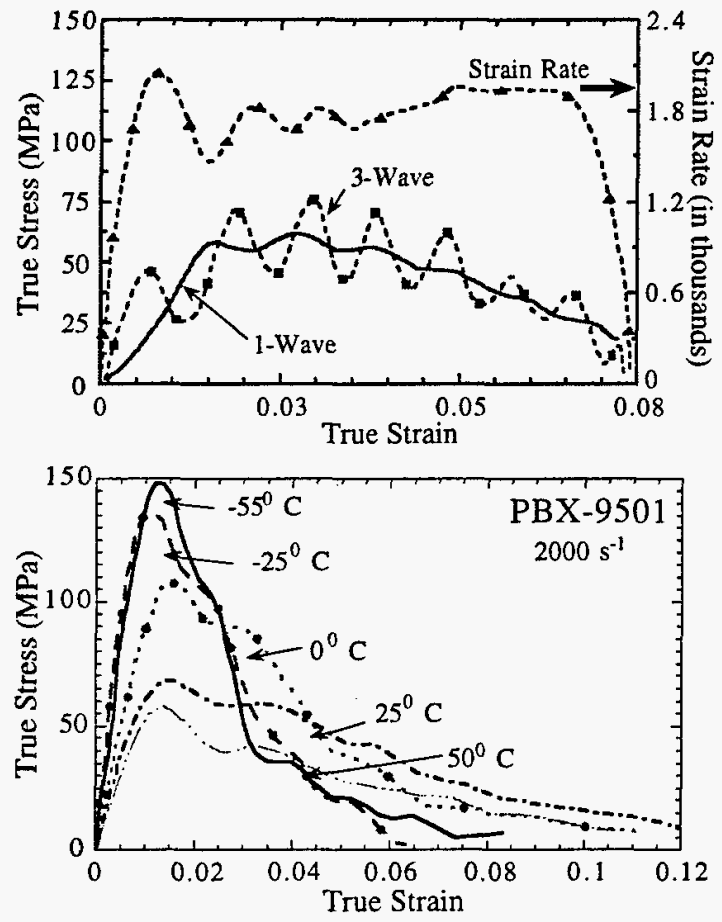

FIGURE 2: Stress-strain response of PBX 9501, a) showing 1- and 3-wave stress curves in addition to the strain rate; and b) as a function of temperature at high strain rate.

Finally a third stress-calculation variation that considers the complete set of three measured bar waveforms, the 3-wave analysis, is simply the average of the 2-wave "front" and the 1-wave "back" stress. A valid, uniaxial Hopkinson bar test requires that the stress state throughout the sample achieve equilibrium during the test and this condition can be checked readily by comparing the 1-wave and 3-wave (or 2-wave) stress-strain response. When the stress state is uniform throughout the sample, then the 3-wave stress oscillates about the 1-wave stress, as seen in Figure 2a. For the current study on PBX 9501 only tests meeting this criterion were deemed acceptable. Previous Hopkinson bar studies of ceramic materials using this 1-wave versus 3-wave comparison have shown quite dramatically that a sample is not in stress equilibrium when divergence is observed(10). In ceramic and cermet materials this divergence correlates very well with the onset of non-uniform plastic flow and/or fracture events.

At high strain rate, the yield strength of PBX 9501 was found to be strongly dependent on temperature as seen in Figure $2 \mathrm{~b}$, decreasing from $150 \mathrm{MPa}$ at $-55^{\circ} \mathrm{C}$ to $60 \mathrm{MPa}$ at $50^{\circ} \mathrm{C}$. These data on PBX 9501 are consistent with the pronounced influence of strain rate and temperature on the mechanical behavior of energetics(1) as well as ductile polymers(11). Coincident with this flow stress increase upon decreasing the temperature is an 9-fold increase in the loading modulus with decreasing temperature at high strain rate. In addition, the failure strain (indicated by a peak in the stress independent of temperature at $\sim 1.5 \%$ strain) is observed to be virtually invariant similar to the findings on Wiegand(7) on various PBX's. This observation suggests a critical tensile initiation criterion in PBX 9501 may be dominant. Attempts to achieve well-posed higher strain rate ( $>$ $5000 \mathrm{~s}^{-1}$ ) data at $298 \mathrm{~K}$ proved unsuccessful. At a strain rate of $7000 \mathrm{~s}^{-1}$ the 1-wave and 3-wave signals were found to be divergent for the entire test (invalidating the stress analysis as discussed previously). Accordingly, all high-rate tests were conducted at $2000 \mathrm{~s}^{-1}$.

The PBX 9501 samples loaded at high-rate behaved essentially elastically to the peak stress level and then suffered catastrophic brittle fracture into fragments. Fractographic analysis using a Scanning Electron Microscope (SEM), revealed that at high-rate PBX 9501 fails via transgranular cleavage through the HMX crystals, as seen in Figure 3a. In several of the larger HMX crystals twins were visible following cleavage fracture (Figure 3b). Further study is required to definitively ascertain the source of these twins. The observation of transgranular fracture in PBX 9501 is similar to that seen following quasi-static loading $(2,7)$. The findings of this study illustrate that advanced material constitutive models for PBX 
9501 will need to incorporate both strain rate and temperature effects on mechanical behavior.

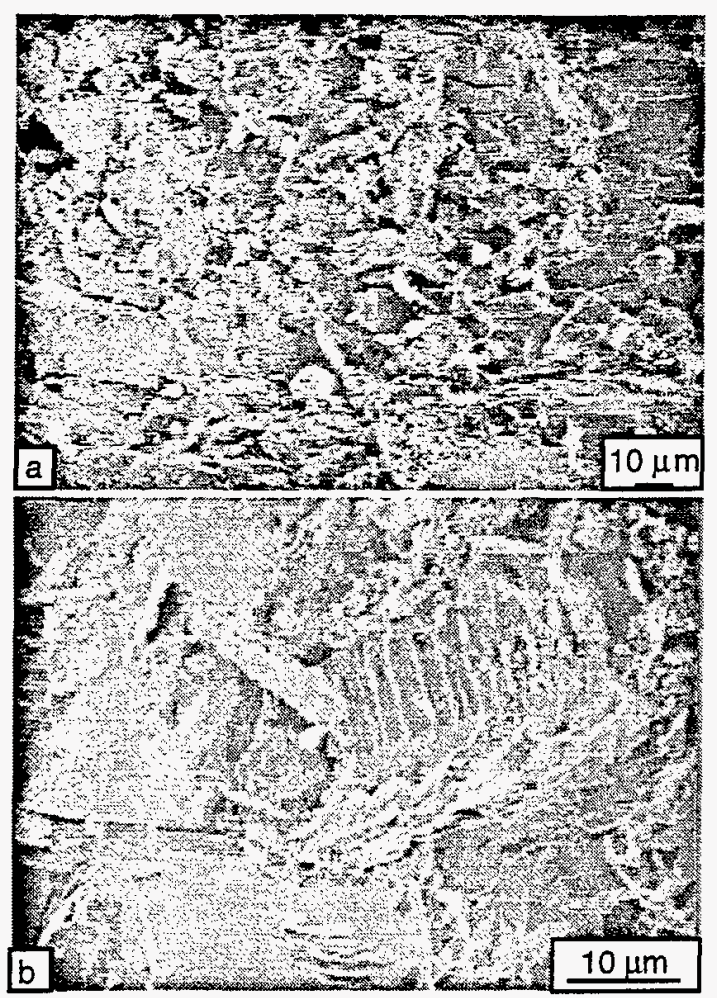

FIGURE 3: Scanning electron micrograph of PBX 9501 following Hopkinson bar testing at $298 \mathrm{~K}$ and a strain rate of $2000 \mathrm{~s}^{-1}$ showing: a) transgranular fracture across the HMX crystals, and b) twins underlying the cleavage fracture in an HMX crystal.

\section{SUMMARY AND CONCLUSIONS}

Based upon this study of strain rate and temperature at high strain rate on the constitutive response of PBX 9501, the following conclusions can be drawn: 1) the compressive stress-strain response of PBX 9501 was found to depend on both the applied strain rate; 0.001 to $-2000 \mathrm{~s}^{-1}$ and the test temperature; -55 to $50^{\circ} \mathrm{C}$ at high-rate, 2) decreasing temperature at $2000 \mathrm{~s}^{-1}$ was found to increase the maximum flow stress in PBX 9501 from 60 to $-150 \mathrm{MPa}$, and 3) PBX 9501 failed at high-strain rate via transgranular cleavage fracture of the HMX crystals.

\section{ACKNOWLEDGMENTS}

This work was supported under the auspices of the United States Department of Energy. The authors acknowledge Tom Zocco for conducting the SEM.

\section{REFERENCES}

1. Hoge, K. G., "The behavior of plastic-bonded explosives under dynamic compressive loads," Appl. Polym. Symp. 5, $19-40$ (1967).

2. Peeters, R. L., "Characterization of plastic bonded explosives," J. Reinf. Plast. Compos. 1, 131-140 (1982)

3. Field, J. E., Palmer, S. J. P., Pope, P. H. et al., "Mechanical properties of PBX's and their behaviour during dropweight impact," in Proc. Eighth Symposium (Int.) on Detonation, edited by J.M. Short (Naval Surface Weapons Center, White Oak, Maryland, USA, 1985), pp. 635-644.

4. Wiegand, D. A., Pinto, J., and Nicolaides, S., "The mechanical response of TNT and a composite, Composition B, of TNT and RDX to compressive stress. I: Uniaxial stress and fracture," J. Energ. Mater. 9, 19-80 (1991).

5. Field, J. E., Bourne, N. K., Palmer, S. J. P. et al., "Hot-spot ignition mechanisms for explosives and propellants," Phil. Trans. R. Soc. Lond. A 339, 269-283 (1992).

6. Palmer, S. J. P., Field, J. E., and Huntley, J. M., "Deformation, strengths and strains to failure of polymer bonded explosives," Proc. R. Soc. Lond. A 440, 399-419 (1993).

7. Wiegand, D. A., "Constant Critical Strain for Failure of Highly Filled Polymer Composites," presented at the 3rd Int. Conf. Def. \& Frac. of Composites, Guildford, U.K., 1995.

8. Funk, D. J., Laabs, G. W., Peterson, P. D. et al., "Measurement of the stress/strain response of energetic materials as a function of strain rate and temperature: PBX 9501 and mock 9501," in Shock Compression of Condensed Matter 1995, edited by S.C. Schmidt and W.C. Tao (American Institute of Physics, Woodbury, New York, 1996), pp. 145-148.

9. Follansbee, P. S. and Frantz, C., "Wave propagation in the SHPB," Trans. ASME: J. Engng Mater. Technol. 105, 61 66 (1983).

10. Blumenthal, W. R. and Gray III, G. T., "Structure-property characterization of shock-loaded $\mathrm{B}_{4} \mathrm{C}-\mathrm{Al}$," Inst. Phys. Conf. Ser. 102, 363-370 (1989).

11. Walley, S. M. and Field, J. E., "Strain rate sensitivity of polymers in compression from low to high strain rates," DYMAT Journal 1, 211-228 (1994). 


\section{M98000621 \\ | |||||||||||||||||||||||||||||||||||||||||||||||||||||||}

Report Number (14) $\frac{\angle A-4 B-2894}{C O N F-97070 \%-}$

Publ. Date (11)

199710

Sponsor Code (18)

DOE/DP, XF

UC Category (19) (IC -741 , DOEIER 